\title{
Heterogeneidade ambiental e estrutura da vegetação arbustivo-arbórea em três áreas de Cerrado sentido restrito no Sudoeste goiano
}

\author{
Environmental hereterogeneity and structure of wood vegetation in three sites \\ of Cerrado sensu stricto in southwestern of Goiás state, Brazil
Gabriel Eliseu Silva', Frederico Augusto Guimarães Guilherme ${ }^{\mathrm{II}}$, Steffan Eduardo Silva Carneiro ${ }^{\mathrm{I}}$, Marcelo Henrique Ongaro Pinheiro ${ }^{\mathrm{III}}$, Wendy Carniello Ferreira ${ }^{\mathrm{IV}}$

\begin{abstract}
Resumo
A variação fitofisionômica do Cerrado brasileiro é intensa e estudos fitossociológicos podem fornecer subsídios sobre quais fatores são responsáveis por essa heterogeneidade ambiental. Nesse sentido, esse estudo teve o objetivo de avaliar a estrutura da vegetação lenhosa de três áreas de cerrado sentido restrito, no município de Jataí - GO, buscando discutir os achados com o histórico de perturbação de cada área e aspectos físicos dos solos. Foram alocadas dez parcelas contíguas de $20 \times 50 \mathrm{~m}$ em cada área, totalizando três hectares de levantamento no total. Incluíram-se na amostragem todos os troncos com diâmetro $\geq 5$ $\mathrm{cm}$, medidos a $30 \mathrm{~cm}$ do solo. As áreas apresentaram diferenças quanto à estrutura da vegetação lenhosa com formações mais abertas e outras mais densas (densidade de 991 a 1859 ind.ha $^{-1}$ e área basal de 10,85 a $\left.17,68 \mathrm{~m}^{2} \cdot \mathrm{ha}^{-1}\right)$. A riqueza florística variou de 70 a 82 espécies. Apesar de haver uma mistura de elementos florísticos savânicos e florestais entre as áreas, detectou-se maior domínio de espécies savânicas. Os padrões florístico e estrutural indicaram heterogeneidade nas comunidades em função de diferenças texturais do solo e incêndios. Isso reforça a importância da preservação de formações savânicas no sudoeste do estado para entender variações estruturais e florísticas e, consequentemente, fornecer informações para outros estudos sobre os aspectos ecológicos relacionados a eles.
\end{abstract}

Palavras-chave: Cerrado sensu stricto; Fitossociologia; Heterogeneidade ambiental; Riqueza e diversidade de espécies lenhosas

\begin{abstract}
The physiognomyvariation of Brazilian Cerrado is intense and phytosociological studies can provide subsidies on which factors are responsible for this environmental heterogeneity. Thus, the objective of this study was to evaluate the structure of the woody vegetation of three sites of Cerrado sensu stricto, in the municipality of Jataí, state of Goiás, Brazil, aiming to discuss the findings with the history of disturbance of each site and physical aspects of the soils. Ten $20 \times 50 \mathrm{~m}$ contiguous plots of were allocated in each area, totaling three hectares of survey in total. We included in the sample all trunks with diameter $\geq 5 \mathrm{~cm}$, measured at $30 \mathrm{~cm}$ of the ground. The sites showed differences in wood structure, ranging from more open to more dense areas (density ranging 991-1859 ind.ha- $\mathrm{a}^{-1}$ and basal area ranging from 10.85 to $17.68 \mathrm{~m}^{2}$.ha $\mathrm{h}^{-1}$ ). The richness in the areas ranged from 70 to 82 as well as the species composition. Although, there is a mix of savanna and forest floristic elements, we detected higher domain of typical savanna species for the three areas. The floristic and structural patterns indicated heterogeneity in the communities, even geographically close, possibly due to soil texture differences. This reinforces the importance of the preservation of savanna formations in the southwest of Goiás state to understand the structural and floristic variations and, consequently, to provide information for other studies on the ecological aspects related to them.
\end{abstract}

Keywords: Brazilian savannah; Phytosociology; Environmental heterogeneity; Woody species richness and diversity

Biólogo, MSc., Programa de Pós-Graduação em Geografia, Universidade Federal de Jataí, BR 364, Km 192, CEP 75801-615, Jataí (GO), Brasil. gabriel_ufg@hotmail.com (ORCID: 0000-0002-9472-5242/ steffan.hb88@hotmail.com (ORCID: 0000-0003-1577-2508)

Biólogo, Dr., Professor da Unidade Acadêmica Especial de Ciências Biológicas, Universidade Federal de Jataí, BR 364, Km 192, CEP 75801-615, Jataí (GO), Brasil. fredericoagg@gmail.com (ORCID: 0000-0002-5623-4127)

III Biólogo, Dr., Professor do Instituto de Ciências Exatas e Biológicas do Pontal, Universidade Federal de Uberlândia, Rua 20, 1600, CEP 38304-402, Ituiutaba (MG), Brasil. mpinheiro@ufu.br (ORCID: 0000-0001-7139-1895)

IV Engenheiro Agrônomo, Dr., Professor da Unidade Acadêmica Especial de Ciências Agrárias, Universidade Federal de Jataí, BR 364, Km 192, CEP 75801-615, Jataí (GO), Brasil.wcferreira_4@hotmail.com (ORCID: 0000-0002-0068-5084) 


\section{Introdução}

O cerrado sentido restrito, uma das fitofisionomias do Cerrado, possui um estrato arbustivo-arbóreo descontínuo e esparso sobre um estrato herbáceo-graminoso contínuo. Geralmente, apresenta evidência de queimadas além de estar, em grande parte, localizado sobre solos pertencentes às classes de Latossolo Vermelho e Latossolo Vermelho Amarelo (RIBEIRO; WALTER, 2008). Segundo Reatto et al. (2008), as áreas de Latossolo ocupam quase $50 \%$ dos mais de 2 milhões de $\mathrm{km}^{2}$ originalmente ocupados pelo bioma e apresentam elevada acidez. Essas fisionomias são as mais propensas ao desmatamento, visto que apresentam elevada aptidão agrícola. Isso não é diferente no estado de Goiás e, mais especificamente no sudoeste goiano, onde o agronegócio predomina e as formações naturais são cada vez menores (MUELLER; MARTINE, 1997; CARMO et al., 2002).

O cerrado sentido restrito é caracterizado por diferentes percentuais de cobertura arbórea em razão das diferentes condições físico-químicas do solo que influenciam na disponibilidade hídrica, fertilidade e profundidade (REATTO et al., 2008). A cobertura arbórea também é influenciada pela frequência e intensidade de queimadas (MIRANDA et al., 2004; RIOS et al., 2018). Devido a isso, a estrutura da vegetação, a distribuição espacial dos indivíduos lenhosos e a composição florística é bastante heterogênea (RIBEIRO; WALTER, 2008). Em virtude da complexidade desses fatores condicionantes, originam-se subdivisões fisionômicas como os cerrados denso, típico e ralo, que são reflexos das variações na forma de agrupamento e no espaçamento entre os indivíduos lenhosos (RIBEIRO; WALTER, 2008).

No entanto, a riqueza e a biodiversidade do Cerrado estão ameaçadas pelo avanço das atividades agropecuárias, que reduziram a cobertura original do Cerrado brasileiro em 60,5\% (SANO et al., 2010). O desenvolvimento da agropecuária no Cerrado ocorre, predominantemente, em áreas sobre solos profundos, bem drenados e com relevo plano (GOMES et al., 2011). Com isso, geram-se fragmentos de vegetação nativa com consequente redução na riqueza de espécies e composição florística (KLINK; MACHADO, 2005). Esse fato, associado à ausência de estudos que abordam as composições florística e estrutural na vegetação de cerrado (MEIRA-NETO; SAPORETTI-JÚNIOR, 2002), principalmente nas regiões sul e sudoeste de Goiás (ANDRADE et al., 2002; AMARAL et al., 2006; PINTO et al., 2009; LIMA et al., 2010; LENZA et al., 2011), demonstram a importância de estudos nos fragmentos savânicos ainda existentes.

Assim, o presente estudo tem como objetivo avaliar e comparar a fitossociologia de três áreas de cerrado sentido restrito, localizadas no município de Jataí - GO. As relações florísticas e a estrutura do componente arbustivo-arbóreo desses três hectares foram comparadas com estudos realizados em outros subtipos fitofisionômicos de cerrado sentido restrito do Brasil Central.

\section{Materiais e métodos}

O estudo foi realizado no ano de 2013, em três fragmentos de cerrado sentido restrito no

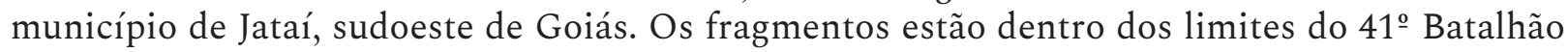

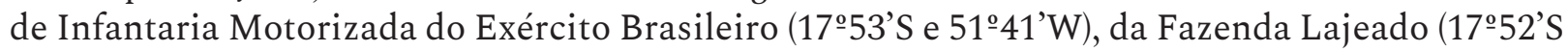
e 513’ W) e da Fazenda Agropecuária Rio Paraíso (17 45’S e 51 32’W) que, a partir de agora, serão denominados BAT, LAJ e FRP, respectivamente. De acordo com o sistema de classificação climática de Köppen (KOTTEK et al., 2006), o clima é tipo Aw - tropical caracterizado por um período seco durante o inverno (abril a setembro) e um período chuvoso durante o verão (novembro a março).

As áreas do BAT e do LAJ encontram-se distantes entre si aproximadamente $6,5 \mathrm{~km}$, enquanto a FRP localiza-se aproximadamente $20 \mathrm{~km}$ das duas áreas. A área do BAT apresenta uma grande quantidade de gramíneas invasoras (Melinis minutiflora P. Beauv. e Urochloa spp.) e sinais de incêndios frequentes, sendo o último registrado em setembro de 2012. A área 
LAJ é um remanescente caracterizado pela transição entre formação savânica-florestal e não há registros de queimadas nos últimos 10 anos. BAT e LAT encontram-se sobre Latossolos. A FRP aparentemente é o remanescente mais conservado, que se encontra sobre Neossolos Quartzarênicos, e também não apresenta registro de queimadas recentes.

Para cada área, coletaram-se três amostras de solo a $0-20 \mathrm{~cm}$ de profundidade para a análise das propriedades físicas do solo. As proporções de areia grossa, areia fina, silte e argila (em \%) foram comparadas por meio de Análise de Variância (ANOVA) seguido pelo teste a posteriori de Tukey, avaliando antes as premissas de normalidade dos dados e homocedasticidade, para aplicação da análise paramétrica (ZAR, 2009), utilizando o programa BioEstat 5.0 (AYRES et al., 2007).

Em cada área foram alocadas 10 parcelas permanentes de $20 \times 50 \mathrm{~m}$, agrupadas em um bloco de $100 \times 100 \mathrm{~m}$ (1 hectare), totalizando três hectares em todo o levantamento. Adotou-se essa conformação em blocos visando atender estudos de populações vegetais (GUILHERME; OLIVEIRA, 2011), e devido ao caráter fragmentado das áreas, limitando a aleatorização das parcelas. Todos os indivíduos vivos com diâmetro $\geq 5 \mathrm{~cm}$ a $30 \mathrm{~cm}$ acima do nível do solo foram medidos com fita métrica, e foram identificados com placas de alumínio numeradas. A altura dos indivíduos foi registrada com o uso de uma vara graduada. Espécies não determinadas no campo tiveram material botânico, em geral no estado estéril, coletado para identificação, por meio de comparação com exsicatas disponíveis no Herbário Jataiense (Universidade Federal de Jata1), literaturas específicas e sites (especialmente Reflora e Species Link), além de registros fotográficos encaminhados a especialistas. Utilizou-se para a classificação das famílias o Angiosperm Phylogenetic Group (2016), sendo a taxonomia revisada e atualizada baseada na Lista da Flora do Brasil (http://floradobrasil.jbrj.gov.br).

Os parâmetros fitossociológicos de densidade, dominância e frequência relativas foram calculados para cada área, e o valor de importância (VI) de cada espécie para todo o levantamento (MUELLER-DOMBOIS; ELLENBERG, 1974). Também foram calculados o índice de diversidade de Shannon (H') e o índice de equabilidade de Pielou (J') (MAGURRAN, 2011). Essas análises foram feitas utilizando planilha eletrônica do Excel. Para comparar a densidade e a área basal entre as três áreas, novamente utilizou-se ANOVA, seguido pelo teste de Tukey. Ao passo que para comparar a altura e o diâmetro dos indivíduos entre as três áreas utilizou-se o teste não paramétrico de Kruskal-Wallis, aplicando a análise a posteriori de Student-Nelman, visto que as premissas da normalidade e homocedasticidade não foram atendidas (ZAR, 2009). Em todos os casos, a normalidade dos dados foi avaliada usando o teste de Shapiro-Wilk e a homogeneidade das variâncias foi confirmada pelo teste de Levene's a 5\% de significância. Para todas essas análises foi utilizado o pacote estatístico BioEstat 5.0 (AYRES et al., 2007).

Foi analisada a distribuição dos indivíduos em classes de tamanho (altura e diâmetro), com os intervalos de classes definidos, por meio da seguinte fórmula:

$$
\mathrm{I}=\frac{\mathrm{A}}{\mathrm{K}}
$$

Em que: $\mathrm{I}$ = incremento em classes ou o intervalo; $\mathrm{A}=$ amplitude dos valores; $\mathrm{K}=$ constante definida pelo algoritmo de Sturges. Essa constante consiste em:

$$
K=1+3,3 \log _{10} n
$$

Em que: $\mathrm{n}$ = é o número total de indivíduos amostrados (SIEGEL, 1975).

As similaridades florística e estrutural foram comparadas entre as três áreas utilizando os índices de Sørensen e Morisita, respectivamente (BROWER; ZAR, 1984). 


\section{Resultados}

A ANOVA mostrou diferenças significativas nas médias das propriedades físicas do solo entre as três áreas (Tabela 1). Os dois cerrados ocorrentes sobre Latossolos (BAT e LAJ), não mostraram diferenças texturais entre eles. Entretanto, ambos apresentaram proporções significativamente menores de areia e significativamente maiores de argila e silte, quando comparados com FRP, que ocorre sobre Neossolos Quartzarênicos.

Tabela 1 - Comparações das propriedades físicas do solo entre as três áreas de Cerrado sentido restrito. Valores são médias \pm desvio padrão, referentes a três amostras de solo para cada área. Médias seguidas de letras diferiram pelo teste de Tukey.

Table 1 - Comparisons of the physical properties of the soil among the three areas of Cerrado stricto sensu. Values are means \pm standard deviation, referring to the three soil samples for each area. Means followed by letters differed by Tukey test.

\begin{tabular}{|c|c|c|c|c|c|}
\hline $\begin{array}{l}\text { Variáveis } \\
\text { físicas do } \\
\text { solo }\end{array}$ & $\begin{array}{c}\text { ANOVA } \\
(\mathbf{G L}=2)\end{array}$ & $\mathbf{P}$ & BAT & LAJ & FRP \\
\hline $\begin{array}{l}\text { Areia Fina } \\
(\%)\end{array}$ & 88,38 & 0,0002 & $\begin{array}{l}10,27 \pm \\
2,56 \mathrm{~b}\end{array}$ & $\begin{array}{l}7,66 \pm \\
0,52 \mathrm{~b}\end{array}$ & $\begin{array}{r}23,14 \pm \\
0,39 \mathrm{a}\end{array}$ \\
\hline $\begin{array}{l}\text { Areia } \\
\text { Grossa (\%) }\end{array}$ & 31,88 & 0,001 & $\begin{array}{l}4,54 \pm \\
3,27 \mathrm{~b}\end{array}$ & $\begin{array}{l}4,09 \pm \\
1,28 \mathrm{~b}\end{array}$ & $\begin{array}{c}15,93 \pm \\
0,60 \mathrm{a}\end{array}$ \\
\hline Argila (\%) & 16,40 & 0,004 & $\begin{array}{c}52,63 \pm \\
4,04 \mathrm{a}\end{array}$ & $\begin{array}{c}58,03 \pm \\
0,66 \mathrm{a}\end{array}$ & $\begin{array}{r}46,13 \pm \\
1,64 \mathrm{~b}\end{array}$ \\
\hline Silte $(\%)$ & 20,74 & 0,003 & $\begin{array}{c}32,56 \pm \\
5,94 \mathrm{a}\end{array}$ & $\begin{array}{c}30,22 \pm \\
0,74 \mathrm{a}\end{array}$ & $\begin{array}{l}14,80 \pm \\
2,14 \mathrm{~b}\end{array}$ \\
\hline
\end{tabular}

Em que: BAT $=41^{\circ}$ Batalhão de Infantaria Motorizada do Exército Brasileiro; LAJ = Fazenda Lajeado; FRP = Fazenda Agropecuária Rio Paraíso.

Amostrou-se um total de 4278 indivíduos, distribuídos em 41 famílias botânicas, 81 gêneros e 131 espécies, considerando as três áreas. Registraram-se 991 indivíduos, 32 famílias, 53 gêneros e 70 espécies no BAT e 1428 indivíduos, 34 famílias, 58 gêneros, 82 espécies na LAJ. Na FRP foram amostradas 1859 indivíduos, 29 famílias, 52 gêneros e 75 espécies (Tabela 2). O índice de diversidade $\left(\mathrm{H}^{\prime}\right)$ apresentou valores de 3,20 no BAT, 3,62 na LAJ e 3,61 na FRP. Para a equabilidade, os valores foram 0,75 no BAT, 0,82 na LAJ e 0,84 na FRP.

No BAT, as famílias que mais contribuíram com a riqueza florística foram Fabaceae (13), Myrtaceae (5), Rubiaceae (5), Erythroxylaceae (4), Malvaceae (4). Bignoniaceae (4). Na LAJ, as famílias com maior riqueza foram: Fabaceae (15), Malpighiaceae (7), Malvaceae (5), Myrtaceae (5), Erythroxylaceae (4) e Vochysiaceae (4). Na FRP, as famílias com maior número de espécies foram: Fabaceae (14), Asteraceae (7), Erythroxylaceae (6), Malpighiaceae (5), Myrtaceae (5) e Vochysiaceae (4).

As espécies com maior VI no BAT foram Butia purpuracens, Curatella americana, Vernonanthura polysphaera, Bowdichia virgilioides e Dimorphandra mollis ( $47,4 \%$ do total). $\mathrm{Na}$ LAJ, as mais importantes foram Curatella americana, Diospyros burchellii, Qualea grandiflora, Annona crassiflora, Butia purpuracens e Qualea multiflora (33,7\% do total), enquanto na FRP houve predomínio de Caryocar brasiliense, Myrcia bella, Qualea grandiflora, Piptocarpha rotundifolia, Lafoensia pacari e Qualea parviflora (30,3\% do total). 


\section{Tabela 2 - Parâmetros fitossociológicos das espécies Arbustivo-arbóreas nas três áreas de Cerrado sentido restrito.}

Table 2 - Phytosociological parameters of woody species in three areas of Cerrado stricto sensu.

\begin{tabular}{|c|c|c|c|c|c|c|c|c|c|c|}
\hline \multirow{2}{*}{ Família/Espécie } & \multicolumn{3}{|c|}{ BAT } & \multicolumn{3}{|c|}{ LAJ } & \multicolumn{3}{|c|}{ FRP } & \multirow[b]{2}{*}{ VI } \\
\hline & DR & DoR & FR & DR & DoR & FR & DR & DoR & FR & \\
\hline Curatella americana $\mathrm{L}$. & 18,97 & 21,9 & 3,94 & 12,04 & 26,49 & 2,58 & 0 & 0 & 0 & 85,92 \\
\hline Butia purpurascens Glassman & 14,03 & 40,94 & 3,54 & 2,66 & 4,92 & 2,58 & 0 & 0 & 0 & 68,67 \\
\hline Myrcia bella Cambess. & 1,72 & 1,45 & 2,76 & 3,57 & 1,35 & 2,58 & 7,53 & 10,99 & 2,49 & 34,45 \\
\hline Caryocar brasiliense Cambess. & 0 & 0 & 0 & 4,62 & 3,03 & 2,33 & 9,04 & 9,6 & 2,49 & 31,11 \\
\hline Qualea grandiflora Mart. & 0,3 & 0,32 & 1,18 & 4,83 & 5,04 & 2,58 & 4,84 & 8,09 & 2,49 & 29,68 \\
\hline Dimorphandra mollis Benth. & 3,53 & 3,11 & 3,94 & 4,9 & 1,88 & 2,58 & 1,08 & 1,15 & 2,24 & 24,42 \\
\hline Diospyros burchellii Hiern & 1,01 & 0,44 & 1,57 & 6,51 & 6,81 & 2,33 & 0,86 & 0,53 & 1,5 & 21,57 \\
\hline Vernonia polysphaera Baker & 10,09 & 3,21 & 3,94 & 1,47 & 0,44 & 2,33 & 0 & 0 & 0 & 21,48 \\
\hline Roupala montana Aubl. & 1,51 & 0,75 & 1,18 & 3,36 & 1,49 & 2,33 & 4,03 & 3,2 & 2,49 & 20,35 \\
\hline Bowdichia virgilioides Kunth & 4,94 & 3,05 & 3,15 & 1,4 & 3,2 & 2,33 & 0 & 0 & 0 & 18,08 \\
\hline Piptocarpha rotundifolia (Less.) Baker & 0 & 0 & 0 & 2,17 & 1,8 & 1,81 & 5,49 & 3,98 & 2,49 & 17,74 \\
\hline Qualea multiflora Mart. & 1,01 & 0,94 & 1,18 & 4,9 & 2,51 & 2,58 & 1,45 & 1,35 & 1,5 & 17,42 \\
\hline Stryphnodendron rotundifolium Mart. & 1,11 & 0,54 & 1,57 & 2,31 & 0,9 & 2,07 & 3,77 & 2,64 & 2,24 & 17,15 \\
\hline Tachigali aurea Tul. & 0,2 & 0,07 & 0,79 & 1,82 & 2,01 & 2,33 & 4,14 & 2,98 & 2,49 & 16,83 \\
\hline Annona crassiflora Mart. & 0,5 & 0,23 & 1,97 & 3,78 & 5,34 & 2,58 & 0,27 & 0,33 & 1,25 & 16,26 \\
\hline Erythroxylum engleri O.E. Schulz & 0,81 & 0,28 & 1,97 & 1,68 & 0,59 & 2,58 & 3,6 & 2,15 & 2,49 & 16,15 \\
\hline Davilla elliptica A. St.Hil. & 0,71 & 0,29 & 1,97 & 3,15 & 1,19 & 2,07 & 2,1 & 1,15 & 2 & 14,62 \\
\hline Connarus suberosus Planch. & 1,51 & 0,71 & 2,76 & 0,98 & 0,61 & 1,81 & 1,94 & 1,6 & 2,49 & 14,41 \\
\hline Styrax ferrugineus Nees \& Mart. & 0,3 & 0,21 & 0,79 & 1,54 & 0,93 & 2,07 & 1,34 & 3,41 & 2,49 & 13,08 \\
\hline Terminalia argentea Mart. & 2,83 & 1,16 & 3,15 & 0,91 & 3,92 & 1,03 & 0 & 0 & 0 & 12,99 \\
\hline Lafoensia pacari A. St.Hil. & 0 & 0 & 0 & 0,28 & 0,36 & 0,78 & 5,06 & 3,67 & 2,49 & 12,63 \\
\hline Tabebuia ochracea (Cham.) Standl. & 0,61 & 0,53 & 0,79 & 0,56 & 0,51 & 1,55 & 3,28 & 2,05 & 2,24 & 12,12 \\
\hline Matayba guianensis Aubl. & 4,44 & 1,44 & 3,15 & 1,12 & 0,32 & 1,55 & 0 & 0 & 0 & 12,02 \\
\hline Qualea parviflora Mart. & 0 & 0 & 0 & 0,21 & 0,33 & 0,78 & 2,85 & 4,84 & 2,49 & 11,5 \\
\hline Tapirira guianensis Aubl. & 0,71 & 0,64 & 2,36 & 3,78 & 1,23 & 2,33 & 0 & 0 & 0 & 11,05 \\
\hline $\begin{array}{l}\text { Astronium fraxinifolium Schott ex } \\
\text { Spreng. }\end{array}$ & 3,73 & 1,5 & 3,54 & 0,42 & 0,77 & 1,03 & 0 & 0 & 0 & 11 \\
\hline Lithrea molleoides (Vell.) Engl. & 3,23 & 2,33 & 3,94 & 0,35 & 0,12 & 0,78 & 0 & 0 & 0 & 10,75 \\
\hline Byrsonima coccolobifolia Kunth & 1,11 & 0,41 & 1,97 & 0,28 & 0,17 & 1,03 & 1,67 & 1,78 & 1,75 & 10,16 \\
\hline Kielmeyera coriacea Mart. \& Zucc. & 0,2 & 0,17 & 0,79 & 0 & 0 & 0 & 3,66 & 2,23 & 2,49 & 9,54 \\
\hline Licania humilis Cham. \& Schltdl. & 0,4 & 0,38 & 1,57 & 1,33 & 2,29 & 2,07 & 0,32 & 0,27 & 0,75 & 9,39 \\
\hline
\end{tabular}


Tabela 2 - Continuação...

Table 2 - Continuation...

\begin{tabular}{|c|c|c|c|c|c|c|c|c|c|c|}
\hline \multirow{2}{*}{ Família/Espécie } & \multicolumn{3}{|c|}{ BAT } & \multicolumn{3}{|c|}{ LAJ } & \multicolumn{3}{|c|}{ FRP } & \multirow[b]{2}{*}{ VI } \\
\hline & DR & DoR & FR & DR & DoR & FR & DR & DoR & FR & \\
\hline Byrsonima basiloba A. Juss. & 0,1 & 0,18 & 0,39 & 2,24 & 1,49 & 2,58 & 0,43 & 0,65 & 1,25 & 9,31 \\
\hline Byrsonima pachyphylla A. Juss. & 0 & 0 & 0 & 1,47 & 0,72 & 2,07 & 1,56 & 1,89 & 1,5 & 9,2 \\
\hline $\begin{array}{l}\text { Eriotheca gracilipes (K. Schum.) A. } \\
\text { Robyns }\end{array}$ & 0 & 0 & 0 & 0,07 & 0,19 & 0,26 & 2,21 & 4,14 & 2 & 8,86 \\
\hline $\begin{array}{l}\text { Ouratea spectabilis (Mart. ex Engl.) } \\
\text { Engl. }\end{array}$ & 0 & 0 & 0 & 0,28 & 0,58 & 1,03 & 2,47 & 1,99 & 2,49 & 8,85 \\
\hline Plathymenia reticulata Benth. & 0,1 & 0,01 & 0,39 & 0,7 & 0,59 & 1,55 & 1,13 & 2,04 & 1,5 & 8,01 \\
\hline Erythroxylum suberosum A. St.Hil. & 0,3 & 0,37 & 1,18 & 0,91 & 0,43 & 1,55 & 0,81 & 0,67 & 1,5 & 7,72 \\
\hline $\begin{array}{l}\text { Eriotheca pubescens (Mart. \& Zucc.) } \\
\text { Schott \& Endl. }\end{array}$ & 1,01 & 0,7 & 1,18 & 0,42 & 1,41 & 1,03 & 0,27 & 0,51 & 1 & 7,54 \\
\hline Byrsonima verbascifolia (L.) DC. & 0,4 & 0,11 & 0,79 & 0,49 & 0,16 & 1,03 & 1,08 & 1,45 & 2 & 7,51 \\
\hline $\begin{array}{l}\text { Pseudobombax tomentosum (Mart. \& } \\
\text { Zucc.) Robyns }\end{array}$ & 2,62 & 2,08 & 2,36 & 0 & 0 & 0 & 0 & 0 & 0 & 7,07 \\
\hline Anadenanthera peregrina (L.) Speg. & 0 & 0 & 0 & 0,21 & 0,63 & 0,78 & 1,51 & 1,31 & 2,49 & 6,92 \\
\hline Leptolobium elegans Vogel & 0,4 & 0,2 & 1,18 & 1,82 & 1,16 & 2,07 & 0 & 0 & 0 & 6,83 \\
\hline $\begin{array}{l}\text { Tachigali subvelutina (Benth.) } \\
\text { OliveiraFilho }\end{array}$ & 0 & 0 & 0 & 1,96 & 3,06 & 1,81 & 0 & 0 & 0 & 6,83 \\
\hline Buchenavia tomentosa Eichler & 0 & 0 & 0 & 0,28 & 0,22 & 0,78 & 1,13 & 2,15 & 2 & 6,55 \\
\hline Erythroxylum sp1. & 0,3 & 0,27 & 0,79 & 0 & 0 & 0 & 1,78 & 1,22 & 2 & 6,36 \\
\hline Xylopia aromatica (Lam.) Mart. & 0 & 0 & 0 & 2,66 & 1,03 & 2,58 & 0 & 0 & 0 & 6,28 \\
\hline Psidium laruotteanum Cambess. & 0,4 & 0,19 & 1,18 & 0 & 0 & 0 & 1,29 & 1,14 & 2 & 6,2 \\
\hline Ouratea hexasperma (A. St.Hil.) Baill. & 0 & 0 & 0 & 0 & 0 & 0 & 2,47 & 1,48 & 2,24 & 6,2 \\
\hline $\begin{array}{l}\text { Stryphnodendron adstringens (Mart.) } \\
\text { Coville }\end{array}$ & 0,1 & 0,06 & 0,39 & 0,21 & 0,04 & 0,26 & 1,45 & 1,16 & 2,24 & 5,92 \\
\hline Myrcia crassifolia (Miq.) Kiaersk. & 1,72 & 0,6 & 3,54 & 0 & 0 & 0 & 0 & 0 & 0 & 5,86 \\
\hline Erythroxylum tortuosum Mart. & 0 & 0 & 0 & 1,05 & 0,47 & 1,81 & 0,43 & 0,36 & 1,25 & 5,36 \\
\hline $\begin{array}{l}\text { Tocoyena formosa (Cham. \& Schltdl.) } \\
\text { K. Schum. }\end{array}$ & 1,21 & 0,66 & 1,97 & 0,28 & 0,07 & 0,78 & 0,05 & 0,02 & 0,25 & 5,29 \\
\hline Plenckia populnea Reissek & 0 & 0 & 0 & 0 & 0 & 0 & 1,78 & 1,36 & 2 & 5,13 \\
\hline Pouteria ramiflora (Mart.) Radlk. & 0 & 0 & 0 & 0,07 & 0,32 & 0,26 & 1,02 & 1,43 & 2 & 5,09 \\
\hline $\begin{array}{l}\text { Tabebuia aurea (Silva Manso) Benth. } \\
\text { \& Hook. f. ex S. Moore }\end{array}$ & 0,5 & 0,37 & 1,57 & 0 & 0 & 0 & 0,7 & 0,49 & 1,25 & 4,88 \\
\hline Guapira noxia (Netto) Lundell & 0 & 0 & 0 & 0,07 & 0,06 & 0,26 & 1,34 & 0,83 & 2,24 & 4,81 \\
\hline Leptolobium dasycarpum Vogel & 1,61 & 0,71 & 1,18 & 0,35 & 0,09 & 0,52 & 0,05 & 0,03 & 0,25 & 4,79 \\
\hline Mouriri elliptica Mart. & 0 & 0 & 0 & 0 & 0 & 0 & 1,29 & 0,94 & 2,49 & 4,73 \\
\hline
\end{tabular}


Tabela 2 - Continuação...

Table 2 - Continuation...

\begin{tabular}{|c|c|c|c|c|c|c|c|c|c|c|}
\hline \multirow{2}{*}{ Família/Espécie } & \multicolumn{3}{|c|}{ BAT } & \multicolumn{3}{|c|}{ LAJ } & \multicolumn{3}{|c|}{ FRP } & \multirow[b]{2}{*}{ VI } \\
\hline & DR & DoR & FR & DR & DoR & FR & DR & DoR & FR & \\
\hline Luehea grandiflora Mart. & 0,81 & 0,97 & 1,97 & 0,28 & 0,15 & 0,52 & 0 & 0 & 0 & 4,7 \\
\hline Alibertia edulis (Rich.) A. Rich. ex DC. & 0,2 & 0,06 & 0,39 & 1,19 & 0,61 & 2,07 & 0 & 0 & 0 & 4,52 \\
\hline Schinus terebinthifolia Raddi & 1,61 & 0,81 & 1,97 & 0 & 0 & 0 & 0 & 0 & 0 & 4,4 \\
\hline Styrax camporum Pohl & 0,81 & 0,35 & 1,97 & 0,35 & 0,24 & 0,52 & 0 & 0 & 0 & 4,23 \\
\hline Erythroxylum sp2. & 0 & 0 & 0 & 0,91 & 0,4 & 2,33 & 0,05 & 0,02 & 0,25 & 3,96 \\
\hline $\begin{array}{l}\text { Hymenaea stigonocarpa Mart. ex } \\
\text { Hayne }\end{array}$ & 0,5 & 1,27 & 1,18 & 0,07 & 0,01 & 0,26 & 0,11 & 0,1 & 0,25 & 3,75 \\
\hline $\begin{array}{l}\text { Couepia grandiflora (Mart. \& Zucc.) } \\
\text { Benth. ex Hook. f. }\end{array}$ & 0 & 0 & 0 & 0,14 & 0,06 & 0,26 & 0,7 & 0,45 & 1,75 & 3,36 \\
\hline Eugenia punicifolia (Kunth) DC. & 0 & 0 & 0 & 0 & 0 & 0 & 0,65 & 0,62 & 1,75 & 3,01 \\
\hline $\begin{array}{l}\text { Chrysophyllum marginatum (Hook. \& } \\
\text { Arn.) Radlk. }\end{array}$ & 0,4 & 0,07 & 1,57 & 0,21 & 0,07 & 0,52 & 0 & 0 & 0 & 2,85 \\
\hline Andira paniculata Benth. & 0 & 0 & 0 & 0,49 & 0,97 & 1,03 & 0,05 & 0,05 & 0,25 & 2,84 \\
\hline Miconia albicans (Sw.) Steud. & 0 & 0 & 0 & 0 & 0 & 0 & 0,59 & 0,42 & 1,75 & 2,76 \\
\hline Casearia sylvestris Sw. & 0,61 & 0,14 & 1,57 & 0 & 0 & 0 & 0,11 & 0,06 & 0,25 & 2,73 \\
\hline Cecropia pachystachya Trécul & 0,71 & 0,34 & 1,18 & 0,07 & 0,06 & 0,26 & 0 & 0 & 0 & 2,61 \\
\hline Eugenia aurata O. Berg & 0,5 & 0,12 & 0,79 & 0,21 & 0,12 & 0,78 & 0 & 0 & 0 & 2,52 \\
\hline Rudgea viburnoides (Cham.) Benth. & 0,2 & 0,25 & 0,39 & 0,28 & 0,44 & 0,78 & 0 & 0 & 0 & 2,35 \\
\hline Strychnos pseudoquina A. St.Hil. & 0 & 0 & 0 & 0,21 & 1,35 & 0,78 & 0 & 0 & 0 & 2,34 \\
\hline Andira cujabensis Benth. & 0 & 0 & 0 & 0 & 0 & 0 & 0,48 & 0,5 & 1,25 & 2,23 \\
\hline Aegiphila verticillata Vell. & 0,1 & 0,01 & 0,39 & 0,42 & 0,11 & 1,03 & 0 & 0 & 0 & 2,08 \\
\hline Emmotum nitens (Benth.) Miers & 0 & 0 & 0 & 0,35 & 0,59 & 1,03 & 0 & 0 & 0 & 1,97 \\
\hline Luehea divaricata Mart. & 0,3 & 0,46 & 1,18 & 0 & 0 & 0 & 0 & 0 & 0 & 1,94 \\
\hline Hancornia speciosa Gomes & 0 & 0 & 0 & 0 & 0 & 0 & 0,32 & 0,31 & 1,25 & 1,88 \\
\hline Machaerium acutifolium Vogel & 0,1 & 0,02 & 0,39 & 0,21 & 0,29 & 0,78 & 0 & 0 & 0 & 1,79 \\
\hline Zanthoxylum rhoifolium Lam. & 0,5 & 0,42 & 0,39 & 0,07 & 0,06 & 0,26 & 0 & 0 & 0 & 1,71 \\
\hline $\begin{array}{l}\text { Protium heptaphyllum (Aubl.) } \\
\text { Marchand }\end{array}$ & 0,1 & 0,03 & 0,39 & 0,28 & 0,18 & 0,52 & 0 & 0 & 0 & 1,5 \\
\hline Myrcia variabilis DC. & 0 & 0 & 0 & 0,35 & 0,08 & 1,03 & 0 & 0 & 0 & 1,47 \\
\hline Annona coriacea Mart. & 0,3 & 0,33 & 0,79 & 0 & 0 & 0 & 0 & 0 & 0 & 1,42 \\
\hline Myrsine guianensis (Aubl.) Kuntze & 0,1 & 0,15 & 0,39 & 0,14 & 0,05 & 0,52 & 0 & 0 & 0 & 1,35 \\
\hline Asteraceae3 & 0 & 0 & 0 & 0 & 0 & 0 & 0,32 & 0,23 & 0,75 & 1,3 \\
\hline Erythroxylum macrophyllum Cav. & 0,3 & 0,19 & 0,79 & 0 & 0 & 0 & 0 & 0 & 0 & 1,28 \\
\hline Mimosa hebecarpa Benth. & 0 & 0 & 0 & 0 & 0 & 0 & 0,27 & 0,48 & 0,5 & 1,24 \\
\hline
\end{tabular}


Tabela 2 - Continuação...

Table 2 - Continuation...

\begin{tabular}{|c|c|c|c|c|c|c|c|c|c|c|}
\hline \multirow{2}{*}{ Família/Espécie } & \multicolumn{3}{|c|}{ BAT } & \multicolumn{3}{|c|}{ LAJ } & \multicolumn{3}{|c|}{ FRP } & \multirow[b]{2}{*}{ VI } \\
\hline & DR & DoR & FR & DR & DoR & FR & DR & DoR & FR & \\
\hline Brosimum gaudichaudii Trécul & 0 & 0 & 0 & 0,07 & 0,12 & 0,26 & 0,11 & 0,06 & 0,5 & 1,11 \\
\hline Aspidosperma macrocarpon Mart. & 0 & 0 & 0 & 0 & 0 & 0 & 0,16 & 0,1 & 0,75 & 1,01 \\
\hline $\begin{array}{l}\text { Agonandra brasiliensis Miers ex } \\
\text { Benth. \& Hook. f. }\end{array}$ & 0,1 & 0,03 & 0,39 & 0 & 0 & 0 & 0,11 & 0,06 & 0,25 & 0,95 \\
\hline $\begin{array}{l}\text { Salacia crassifolia (Mart. ex Schult.) } \\
\text { G. Don }\end{array}$ & 0 & 0 & 0 & 0 & 0 & 0 & 0,11 & 0,34 & 0,5 & 0,94 \\
\hline Byrsonima crassifolia (L.) Kunth & 0 & 0 & 0 & 0,21 & 0,13 & 0,52 & 0 & 0 & 0 & 0,86 \\
\hline $\begin{array}{l}\text { Moquiniastrum polymorphum (Less.) } \\
\text { G. Sancho }\end{array}$ & 0 & 0 & 0 & 0 & 0 & 0 & 0,16 & 0,12 & 0,5 & 0,78 \\
\hline Rourea induta Planch. & 0 & 0 & 0 & 0 & 0 & 0 & 0,16 & 0,08 & 0,5 & 0,74 \\
\hline Myrcia sp. & 0 & 0 & 0 & 0,14 & 0,07 & 0,52 & 0 & 0 & 0 & 0,73 \\
\hline Cybistax antisyphilitica (Mart.) Mart. & 0 & 0 & 0 & 0,07 & 0,04 & 0,26 & 0,05 & 0,02 & 0,25 & 0,69 \\
\hline $\begin{array}{l}\text { Pseudobombax longiflorum (Mart. \& } \\
\text { Zucc.) A. Robyns }\end{array}$ & 0 & 0 & 0 & 0,07 & 0,02 & 0,26 & 0,05 & 0,04 & 0,25 & 0,69 \\
\hline Diplusodon virgatus Pohl. & 0,2 & 0,08 & 0,39 & 0 & 0 & 0 & 0 & 0 & 0 & 0,68 \\
\hline $\begin{array}{l}\text { Guettarda viburnoides Cham. \& } \\
\text { Schltdl. }\end{array}$ & 0,2 & 0,08 & 0,39 & 0 & 0 & 0 & 0 & 0 & 0 & 0,68 \\
\hline Coccoloba mollis Casar. & 0,2 & 0,05 & 0,39 & 0 & 0 & 0 & 0 & 0 & 0 & 0,64 \\
\hline Erythroxylum sp3. & 0 & 0 & 0 & 0 & 0 & 0 & 0,16 & 0,14 & 0,25 & 0,55 \\
\hline Hymenaea martiana Hayne & 0,1 & 0,06 & 0,39 & 0 & 0 & 0 & 0 & 0 & 0 & 0,55 \\
\hline Jacaranda cuspidifolia Mart. & 0,1 & 0,05 & 0,39 & 0 & 0 & 0 & 0 & 0 & 0 & 0,54 \\
\hline Ocotea sp. & 0,1 & 0,04 & 0,39 & 0 & 0 & 0 & 0 & 0 & 0 & 0,53 \\
\hline Salvertia convallariodora A. St.Hil. & 0 & 0 & 0 & 0,07 & 0,2 & 0,26 & 0 & 0 & 0 & 0,53 \\
\hline Bauhinia ungulata $\mathrm{L}$. & 0,1 & 0,03 & 0,39 & 0 & 0 & 0 & 0 & 0 & 0 & 0,53 \\
\hline Myrcia tomentosa (Aubl.) DC. & 0,1 & 0,03 & 0,39 & 0 & 0 & 0 & 0 & 0 & 0 & 0,52 \\
\hline Senegalia polyphylla (DC.) Britton & 0,1 & 0,03 & 0,39 & 0 & 0 & 0 & 0 & 0 & 0 & 0,52 \\
\hline Randia armata (Sw.) DC. & 0,1 & 0,02 & 0,39 & 0 & 0 & 0 & 0 & 0 & 0 & 0,51 \\
\hline Tabebuia roseoalba (Ridl.) Sandwith & 0,1 & 0,02 & 0,39 & 0 & 0 & 0 & 0 & 0 & 0 & 0,51 \\
\hline Vochysia cinnamomea Pohl & 0 & 0 & 0 & 0 & 0 & 0 & 0,05 & 0,15 & 0,25 & 0,45 \\
\hline Magonia pubescens A. St.Hil. & 0 & 0 & 0 & 0,07 & 0,08 & 0,26 & 0 & 0 & 0 & 0,41 \\
\hline Asteraceae2 & 0 & 0 & 0 & 0 & 0 & 0 & 0,11 & 0,05 & 0,25 & 0,4 \\
\hline $\begin{array}{l}\text { Pseudobombax marginatum (A.St.-Hil., } \\
\text { Juss. \& Cambess.) A.Robyns }\end{array}$ & 0 & 0 & 0 & 0,07 & 0,07 & 0,26 & 0 & 0 & 0 & 0,4 \\
\hline Andira sp. & 0 & 0 & 0 & 0 & 0 & 0 & 0,05 & 0,06 & 0,25 & 0,36 \\
\hline
\end{tabular}


Tabela 2 - Conclusão...

Table 2 - Conclusion...

\begin{tabular}{|c|c|c|c|c|c|c|c|c|c|c|}
\hline \multirow{2}{*}{ Família/Espécie } & \multicolumn{3}{|c|}{ BAT } & \multicolumn{3}{|c|}{ LAJ } & \multicolumn{3}{|c|}{ FRP } & \multirow[b]{2}{*}{ VI } \\
\hline & DR & DoR & FR & DR & DoR & FR & DR & DoR & FR & \\
\hline $\begin{array}{l}\text { Guapira graciliflora (Mart. ex J.A. } \\
\text { Schmidt) Lundell }\end{array}$ & 0 & 0 & 0 & 0 & 0 & 0 & 0,05 & 0,06 & 0,25 & 0,36 \\
\hline Byrsonima sericea DC. & 0 & 0 & 0 & 0,07 & 0,02 & 0,26 & 0 & 0 & 0 & 0,35 \\
\hline Psidium sp. & 0 & 0 & 0 & 0,07 & 0,02 & 0,26 & 0 & 0 & 0 & 0,35 \\
\hline Platypodium elegans Vogel & 0 & 0 & 0 & 0,07 & 0,02 & 0,26 & 0 & 0 & 0 & 0,35 \\
\hline Salacia sp. & 0 & 0 & 0 & 0,07 & 0,02 & 0,26 & 0 & 0 & 0 & 0,35 \\
\hline Acacia sp. & 0 & 0 & 0 & 0 & 0 & 0 & 0,05 & 0,04 & 0,25 & 0,35 \\
\hline Copaifera langsdorffii Desf. & 0 & 0 & 0 & 0,07 & 0,02 & 0,26 & 0 & 0 & 0 & 0,34 \\
\hline Tabebuia sp. & 0 & 0 & 0 & 0,07 & 0,02 & 0,26 & 0 & 0 & 0 & 0,34 \\
\hline Byrsonima intermedia A. Juss. & 0 & 0 & 0 & 0,07 & 0,01 & 0,26 & 0 & 0 & 0 & 0,34 \\
\hline Baccharis dracunculifolia DC. & 0 & 0 & 0 & 0 & 0 & 0 & 0,05 & 0,04 & 0,25 & 0,34 \\
\hline Heteropterys byrsonimifolia A. Juss. & 0 & 0 & 0 & 0 & 0 & 0 & 0,05 & 0,04 & 0,25 & 0,34 \\
\hline $\begin{array}{l}\text { Anadenanthera colubrina (Vell.) } \\
\text { Brenan }\end{array}$ & 0 & 0 & 0 & 0 & 0 & 0 & 0,05 & 0,03 & 0,25 & 0,33 \\
\hline Asteraceae1 & 0 & 0 & 0 & 0 & 0 & 0 & 0,05 & 0,02 & 0,25 & 0,33 \\
\hline $\begin{array}{l}\text { Psidium salutare var. pohlianum (O. } \\
\text { Berg) Landrum }\end{array}$ & 0 & 0 & 0 & 0 & 0 & 0 & 0,05 & 0,02 & 0,25 & 0,33 \\
\hline Myrtaceae1 & 0 & 0 & 0 & 0 & 0 & 0 & 0,05 & 0,02 & 0,25 & 0,32 \\
\hline Vernonia sp. & 0 & 0 & 0 & 0 & 0 & 0 & 0,05 & 0,02 & 0,25 & 0,32 \\
\hline
\end{tabular}

Em que: $\mathrm{BAT}=41^{\circ}$ Batalhão de Infantaria Motorizada do Exército Brasileiro; LAJ = Fazenda Lajeado; FRP = Fazenda Agropecuária Rio Paraíso; DR = Densidade relativa; DoR = Dominância relativa; FR = Frequência relativa; VI = Valor de importância total das três comunidades. Espécies em ordem decrescente de VI e valores relativos em $\%$.

Do total de espécies registradas, 25 ocorreram nas três comunidades estudadas, 18 foram exclusivas do BAT, 16 da LAJ e 26 da FRP (Tabela 2). As maiores semelhanças florísticas e estruturais ocorreram entre BAT e LAJ, enquanto FRP e BAT apresentaram as menores similaridades (Tabela $3)$.

No BAT, as famílias que mais contribuíram com a riqueza florística foram Fabaceae (13), Myrtaceae (5), Rubiaceae (5), Erythroxylaceae (4), Malvaceae (4). Bignoniaceae (4). Na LAJ, as famílias com maior riqueza foram: Fabaceae (15), Malpighiaceae (7), Malvaceae (5), Myrtaceae (5), Erythroxylaceae (4) e Vochysiaceae (4). Na FRP, as famílias com maior número de espécies foram: Fabaceae (14), Asteraceae (7), Erythroxylaceae (6), Malpighiaceae (5), Myrtaceae (5) e Vochysiaceae (4).

Houve diferenças significativas entre as três áreas para os valores médios de densidade de plantas lenhosas $(\mathrm{F}=20,20 ; \mathrm{p}<0,0001 ; \mathrm{GL}=2)$ e área basal $(\mathrm{F}=26,09 ; \mathrm{p}<0,0001 ; \mathrm{GL}=2)($ Tabela 4$) . \mathrm{O}$ número médio de indivíduos na FRP foi significativamente maior do que na LAJ, que por sua vez foi significativamente maior do que na BAT. Enquanto a área basal média foi significativamente maior na LAJ do que nas outras duas áreas (BAT e FRP). A altura e o diâmetro médio das árvores foram significantemente menores na FRP $(2,78 \pm 0,18 \mathrm{~m} ; 8,15 \pm 0,26 \mathrm{~cm})$ em comparação com BAT $(3,68 \pm 0,57 \mathrm{~m} ; 12,19 \pm 1,13 \mathrm{~cm})$ e LAJ $(4,03 \pm 0,47 \mathrm{~m} ; 10,79 \pm 1,00 \mathrm{~cm})$, respectivamente $\left(\mathrm{H}_{(2,30)=} 17,84, \mathrm{p}\right.$ $\left.<0,01 ; \mathrm{H}_{(2,30)}=21,99, \mathrm{p}<0,01\right)$. 
Tabela 3 - Valores de similaridade entre as três áreas de Cerrado sentido restrito do município de Jataí - GO.

Table 3 - Values of similarity between the areas of three Cerrado stricto sensu of the municipality of Jataí, GO state.

\begin{tabular}{cccc}
\hline & BAT & LAJ & FRP \\
\hline BAT & & $0,60^{*}$ & $0,08^{*}$ \\
LAJ & $0,62^{+}$ & & $0,47^{\ddagger}$ \\
FRP & $0,42^{+}$ & $0,57^{+}$ & \\
\hline
\end{tabular}

Em que: $B A T=41^{\circ}$ Batalhão de Infantaria Motorizada do Exército Brasileiro; LAJ = Fazenda Lajeado; FRP = Fazenda Agropecuária Rio Paraíso; ${ }^{\dagger}=$ índice de Sorensen; ${ }^{\ddagger}=$ índice de Morisita.

Tabela 4 - Comparações dos parâmetros fitossociológicos (densidade, área basal, altura e diâmetro) entre as três áreas de Cerrado sentido restrito. Valores são médias \pm desvio padrão. Médias seguidas de letras iguais não diferiram pelo teste de Tukey (para a densidade e a área basal) ou de Kruskal-Wallis (para a altura e o diâmetro).

Table 4: Comparisons of the phytosociological parameters (density, basal area, height and diameter) among the three areas of Cerrado stricto sensu. Values are means \pm standard deviation. Means followed by equal letters dif not differ by Tukey test (for a density and a basal area) or Kruskal-Wallis (for a height and diameter).

\begin{tabular}{|c|c|c|c|c|c|}
\hline $\begin{array}{c}\text { Parâmetros } \\
\text { fitossociológicos }\end{array}$ & $\begin{array}{l}\text { ANOVA } \\
(\mathbf{G L}=2)\end{array}$ & $P$ & BAT & LAJ & FRP \\
\hline Densidade (ind.ha ${ }^{-1}$ ) & 20,20 & 0,0001 & $991 \mathrm{c}$ & $1428 \mathrm{~b}$ & $1859 \mathrm{a}$ \\
\hline Área basal $\left(\mathrm{m}^{2} \cdot \mathrm{ha}^{-1}\right)$ & 26,09 & 0,0001 & $14,81 \mathrm{~b}$ & $\begin{array}{c}17,68 \\
\mathrm{a}\end{array}$ & $\begin{array}{c}10,85 \\
b\end{array}$ \\
\hline Altura (m) & 17,84 & 0,01 & $\begin{array}{l}3,68 \pm \\
0,57 \mathrm{a}\end{array}$ & $\begin{array}{l}4,03 \pm \\
0,47 \mathrm{a}\end{array}$ & $\begin{array}{l}2,78 \pm \\
0,18 \mathrm{~b}\end{array}$ \\
\hline Diâmetro (cm) & 21,99 & 0,01 & $\begin{array}{c}12,19 \pm \\
1,13 \mathrm{a}\end{array}$ & $\begin{array}{c}10,79 \\
\pm 1,00 \\
\text { a }\end{array}$ & $\begin{array}{l}8,15 \pm \\
0,26 b\end{array}$ \\
\hline
\end{tabular}

Em que: BAT $=41^{\circ}$ Batalhão de Infantaria Motorizada do Exército Brasileiro; LAJ = Fazenda Lajeado; FRP = Fazenda Agropecuária Rio Paraíso.

As áreas do LAJ e FRP apresentaram valores de densidade relativamente elevados, quando comparados aos dados compilados por Assunção e Felfili (2004) e Gomes et al. (2011). Esse fato está relacionado ao bom estado de conservação dessas áreas, não apresentando indícios de corte de árvores ou queimadas. Segundo Miranda et al. (2002), o estrato graminoso abundante no cerrado sentido restrito serve de material combustível para queimadas recorrentes, as quais modificam a estrutura da vegetação arbustivo-arbórea, refletindo em redução de biomassa, com o aumento das taxas de mortalidade dos indivíduos lenhosos e da redução na taxa de 
As três áreas apresentaram distribuição de frequência nas classes de diâmetro tendendo à exponencial negativa, ou J-reverso, com a maioria dos indivíduos concentrados nas duas primeiras classes diamétricas (61,55\% no BAT, 76,55\% na LAJ e 72,29\% na FRP) (Figura 1). Para as classes de altura houve tendência à distribuição normal para o BAT, embora haja oscilação na quantidade de indivíduos encontrada nas classes de altura a 3,57 m, e para a LAJ. Para a FRP, 90\% dos indivíduos alcançaram, no máximo 4 metros de altura e, por isso, se distribuíram nas cinco primeiras classes (Figura 2).

Figura 1 - Distribuição de frequência nas classes de diâmetro dos indivíduos Arbustivoarbóreos amostrados nas áreas de Cerrado sentido restrito do município de Jataí GO.

Figure 1- Frequency distribution in diameter classes of woody individuals sampled in areas of Cerrado stricto sensu of the municipality of Jataí, GO state.
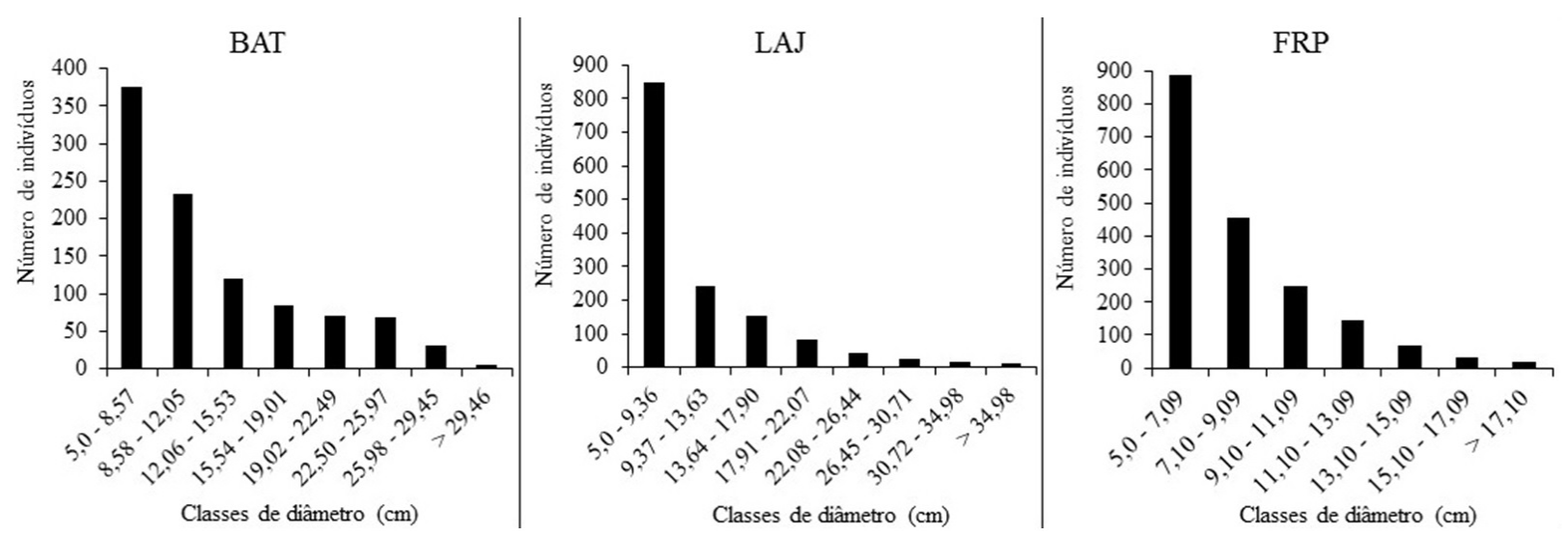

Fonte: Eliseu (2018).

Figura 2 - Distribuição de frequência nas classes de altura dos indivíduos Arbustivoarbóreos amostrados nas áreas de Cerrado sentido restrito do município de Jataí - GO.

Figure 2 - Frequency distribution in height classes of woody individuals sampled in areas of Cerrado stricto sensu of the municipality of Jataí, GO state.
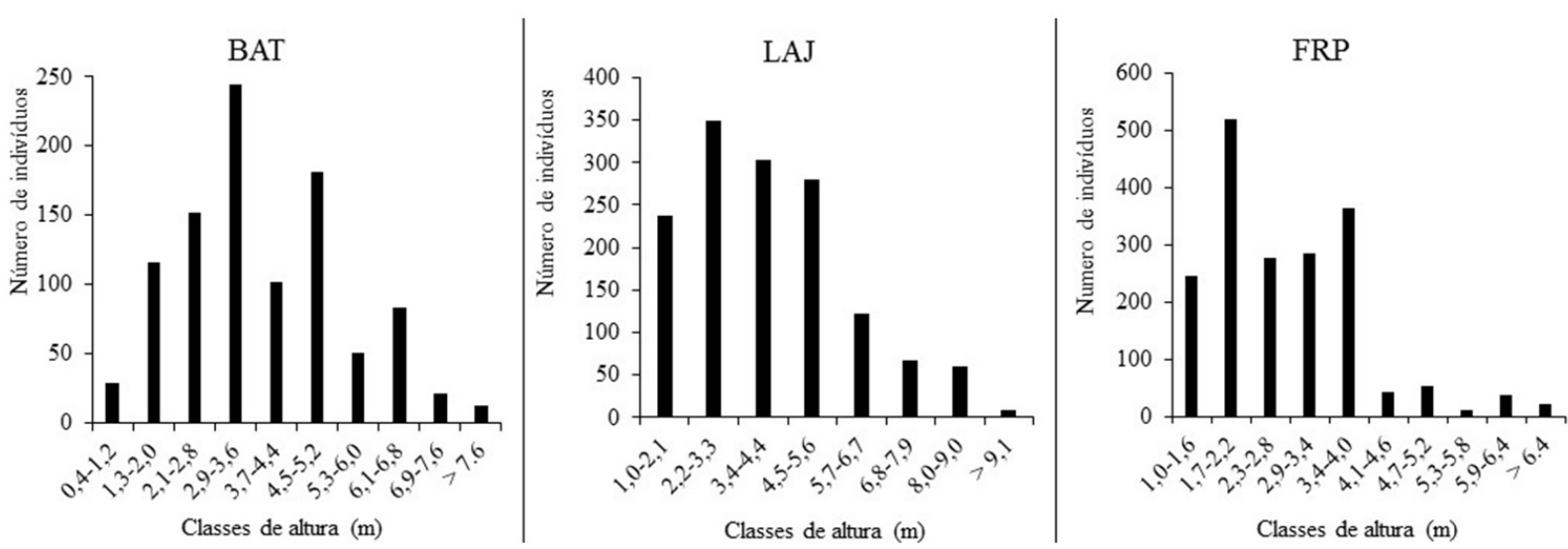

Fonte: Eliseu (2018). 


\section{Discussão}

A riqueza de espécies, a diversidade e a equabilidade registrados para as três comunidades estudadas estão dentro dos valores registrados em outros levantamentos em áreas de cerrado sentido restrito no Distrito Federal (ASSUNÇÃO; FELFILI, 2004), em Minas Gerais (BALDUÍNO

et al., 2005), no Mato Grosso (FELFILI et al., 2002; MARACAHIPES et al., 2011), no Tocantins (MEDEIROS; WALTER, 2012) e em Goiás (LIMA et al., 2010). Da mesma forma, o atual estudo também compartilha algumas famílias botânicas com maior número de espécies (Fabaceae, Malvaceae, Myrtaceae e Vochysiaceae), com outros trabalhos realizados em cerrado sentido restrito em Goiás (PINTO et al., 2009; LIMA et al., 2010), no Distrito Federal (ASSUNÇÃO; FELFILI, 2004) e em Minas Gerais (GIÁCOMO et al., 2013). Andrade et al. (2002) verificaram que Fabaceae (9) e Vochysiaceae (6) foram as famílias com as maiores riquezas. Fabaceae apresenta maior adaptabilidade em regiões com baixo teor de nitrogênio pela capacidade de nodulação de suas espécies. Dessa forma, acabam tendo vantagem sobre as demais espécies, principalmente no Cerrado, uma vez que o solo, na maioria das vezes, é pobre em nutrientes (DOBEREINER, 1984; DOWLING; BROUGHTON, 1986). Vochysiaceae, por sua vez, tem ocorrido com grande representatividade e está entre as mais importantes quando se trata de estudos de fitossociologia e florística em áreas do Cerrado (NERI et al., 2007). Isso porque a família tem espécies tipicamente acumuladoras de alumínio, conferindo vantagens competitivas às suas espécies em solos ácidos, que são comuns no Cerrado brasileiro (HARIDASAN, 2000).

Tratando-se de riqueza de espécies, FRP parece possuir flora lenhosa com características próprias, composta por espécies lenhosas típicas de formações savânicas, principalmente de cerrado sentido restrito, como Caryocar brasiliense, Myrcia bella, Qualea grandiflora, Piptocarpha rotundifolia, Lafoensia pacari, Qualea parviflora, Roupala montana, Tachigali aurea, Stryphnodendron rotundifolium e Kielmeyera coriacea. Essas espécies foram as mais importantes na FRP e estão entre aquelas mais frequentemente encontradas e consideradas características de cerrado sentido restrito no Brasil Central (RATTER et al., 2003). FRP também compartilha espécies fraxinifolium, Myrsine guianensis, Terminalia argentea, Tapirira guianensis e Zanthoxylum rhoifolium (MENDONÇA et al., 2008). Acreditase que a proximidade geográfica entre BAT e LAJ, a presença de formações florestais próximas e, consequentemente, a semelhança nas condições ambientais locais, como a ocorrência de Latossolos, têm influenciado nas semelhanças florísticas, a partir da dispersão de propágulos entre remanescentes. Por outro lado, a diferença florística dessas duas áreas com FRP, reforça a presença de heterogeneidade em cerrado sentido restrito, mesmo em áreas próximas, como descrito por Oliveira-Filho e Ratter (2002).

Em torno de 65\% das 30 espécies registradas com maior VI no presente estudo são comumente encontradas em áreas de cerrado sentido restrito sobre solos profundos (RATTER et al., 2003; MENDONÇA et al., 2008; LENZA et al., 2015). Dentre essas espécies mais importantes (VI), merecem destaque Caryocar brasiliense, Curatella americana, Dimorphandra mollis, Myrcia bella e Qualea grandiflora. Todas tratadas como espécies típicas de cerrado sentido restrito (MENDONÇA et al., 2008), sendo amplamente encontradas em formações savânicas (RATTER etal., 2003). Por outro lado, Butia purpuracens foi a espécie mais importante no BAT e a quinta mais importante no LAJ. Essa palmeira é endêmica do sudoeste de Goiás e regiões limítrofes, sendo sua distribuição de forma agregada predominando em áreas abertas nas quais a intensidade luminosa é maior (GUILHERME; OLIVEIRA, 2011; GUILHERME et al., 2015), e ainda sobre Latossolos, visto que a espécie não ocorreu sobre Neossolos, na FRP.

Segundo Ribeiro e Walter (2008), a estrutura arbórea em cerrado sentido restrito é influenciada pelas condições edáficas, $\mathrm{pH}$ e saturação de alumínio, fertilidade, condições hídricas e profundidade do solo, além da frequência por queimadas e ações antrópicas. Marimon-Junior e Haridasan (2005) ao compararem os componentes físico-químicos do solo de cerradão e cerrado sentido restrito não encontraram diferenças nas variáveis químicas, explicando que a existência das duas fitofisionomias esteja associada à composição granulométrica do solo. Esses autores presumiram que o solo sob cerradão (mais argiloso) teria maior capacidade de retenção de água disponível, favorecendo o processo de produção de biomassa. As maiores áreas basais registradas no BAT e LAJ, podem ser reflexo das condições ambientais, principalmente edáficas, visto que os solos são mais argilosos, tipicamente encontrados em Latossolos. 
recrutamento (MOREIRA, 2000; MIRANDA et al., 1996; 2004; HOFFMANN; MOREIRA, 2002). Assim, considerando que o BAT apresenta estrato graminoso bem mais abundante do que na LAJ e na FRP, sugeriu-se que no BAT há maior acúmulo de material combustível em relação as outras duas áreas, que contribuiu com uma queimada mais intensa no ano anterior e causou maiores danos e mortalidade de indivíduos lenhosos. Por mais que não tenha sido mensurado, era visível uma quantidade de indivíduos mortos em pé e carbonizados pouco tempo antes da amostragem da vegetação, indicando que interferência por fogo é frequente nesta área. Dessa forma, o menor valor de densidade no BAT, entre as três áreas estudadas, pode também estar associado à ocorrência de queimadas intensas. Entretanto, estudos de dinâmica vêm sendo conduzidos para verificar o comportamento estrutural da comunidade vegetal nas três áreas ao longo do tempo.

Os valores de densidade e de área basal da LAJ se assemelham também aos encontrados por Solórzano et al. (2012), em três áreas de cerradão (Paracatu - MG; Dois Irmãos do Buriti - MS e Parque Nacional das Setes Cidades - PI) distribuídas ao longo do Cerrado. Por outro lado, a menor área basal registrada na FRP parece estar condicionada à presença do Neossolos, que em geral são mais rasos e pobres em nutrientes do que os Latossolos (SPERA et al., 2005) e condiciona a ocorrência de uma vegetação de porte mais baixo, uma vez que indivíduos de grande porte não se sustentariam diante da condição edáfica local (MARIMON-JÚNIOR; HARIDASAN, 2005).

Em relação à distribuição diamétrica, a ocorrência ocasional de queimadas e a ausência de corte seletivo no BAT, influenciou na maior quantidade de árvores mais grossas (mais de $50 \%$ com diâmetro acima de $10 \mathrm{~cm}$ ), uma vez que árvores mais finas reduzem a chance de sobrevivência em áreas com queimadas frequentes (MIRANDA et al., 2002; RIOS et al., 2018). Por outro lado, as condições edáficas e a ausência de queimadas na FRP, alterou o padrão de distribuição diamétrica, com a maior parte dos indivíduos $(80 \%)$ com diâmetro de até $10 \mathrm{~cm}$. Por mais que ocorressem essas variações, os padrões encontrados foram semelhantes aos observados em outras áreas de cerrado sentido restrito, como em Nova Xavantina - MT (GOMES et al., 2011), em Água Boa - MT (FELFILI et al., 2002) e em Brasília - DF (ANDRADE et al., 2002).

As distribuições em classes de altura para BAT e LAJ foram semelhantes aos padrões encontrados em cerrados sentido restrito no Mato Grosso (GOMES et al., 2011). Assim, se as condições ambientais se mantiverem ao longo do tempo, principalmente, a ausência de incêndios florestais, e forem suficientes para o aumento de biomassa e de espécies nessa comunidade savânica pode prosseguir com a sucessão ecológica. Com isso, alterações na estrutura e na composição florística poderão torná-la cada vez mais rica e abundante em espécies florestais, como encontrado nos cerradões (RIBEIRO; WALTER, 2008). Para a FRP, pouco mais de $90 \%$ são de pequeno porte $(\leq 4 \mathrm{~m})$, e os fatores envolvidos nas variações florísticas e estruturais, se devem à incidência de queimadas pretéritas e às condições edáficas locais, como constatado nas análises das propriedades físicas do solo.

\section{Conclusão}

A vegetação arbustivo-arbórea das três áreas estudadas apresentou composição florística, riqueza e diversidade de espécies similares àquelas encontradas em outras fitofisionomias de cerrado denso, cerrado típico e cerradão, com ampla ocorrência de espécies típicas de formações savânicas. A área do LAJ em especial, apresentou maior número de espécies e indivíduos típicos de formações florestais, o que pode ser explicado pela proximidade com fragmentos florestais e restrição de queimadas recentes. Esses fatores associados, certamente permitem esse avanço no estágio sucessional.

No BAT, as queimadas frequentes podem influenciar na menor densidade registrada, enquanto a ausência de corte seletivo e as condições edáficas permitem a manutenção de árvores mais grossas que contribuíram para o segundo maior valor de área basal. BAT e LAJ 
apresentaram maiores similaridades florística e estrutural, explicado pela semelhança na textura do solo constatada, sendo que ambas ocorrem sobre Latossolos. Ao passo que FRP, sobre Neossolos e protegido de queimadas, apresentou menor porte de árvores, densidade superior e menor similaridade com as outras duas áreas, ressaltando diferenças na estrutura da vegetação e reforçando essa heterogeneidade ambiental existente nos cerrados da região, mesmo próximas geograficamente.

\section{Agradecimentos}

Os autores agradecem ao CNPq e a FAPEG no âmbito do projeto PELD Jataí (Processo № 2012/10267 00 1108), pelo apoio logístico e financeiro. Agradecemos aos graduandos em biologia José Ricardo G. Constantino e Raúl Sanchez, pela ajuda na coleta de dados. GES e FAGG são gratos ao CNPq pelas bolsas de Mestrado e de Produtividade em Pesquisa - PQ2 (Processo No 303159/2015-4), respectivamente.

\section{Referências}

AMARAL, A. G. et al. Fitossociologia de uma área de cerrado rupestre na Fazenda Sucupira, Brasília, DF. Cerne, Lavras, v. 12, n. 4, p. 350-359, 2006.

ANDRADE, L. A. Z. et al. Fitossociologia de uma área de cerrado denso na RECOR-IBGE, Brasília-DF. Acta Botanica Brasilica, Belo Horizonte, v. 16, n. 2, p. 225-240, 2002.

ANGIOSPERN PLYLOGENY GROUP. An update the Angiospern Plylogeny Group classification for the orders and families of flowering plants. Botanical Journal of the Linnean Society, Hoboken, v. 181, p. 1-20, 2016.

ASSUNÇÃO, S. L.; FELFILI, J. M. Fitossociologia de um fragmento de cerrado sensu stricto na APA do Paranoá, DF, Brasil. Acta Botanica Brasilica, Belo Horizonte, v. 18, n. 4, p. 903-909, 2004.

AYRES, M. et al. Bioestat 5.0: aplicações estatísticas nas áreas das ciências biomédicas. Belém: [s.n.], 2007.

BALDUÍNO, A. P. D. C. et al. Fitossociologia e análise comparativa da composição florística do cerrado da flora de Paraopeba-MG. Revista Árvore, Viçosa, MG, v. 29, n. 1, p. 25-34, 2005.

BROWER, J. E.; ZAR, J. H. Field and laboratory methods for general ecology. Boston: Wm. C. Brown, 1984.

CARMO, R. L. et al. Agroindústria, população e ambiente no sudoeste de Goiás. In: ENCONTRO DA ASSOCIAÇÃO BRASILEIRA DE ESTUDOS POPULACIONAIS, 13., 2002, Ouro Preto. Anais... Ouro Preto: [s.n.], 2002. Disponível em: <http://www.abep.nepo.unicamp.br/docs/anais/ pdf/2002/ GT_MA_ST13_Carmo_texto.pdf> Acesso em: 03 maio 2016.

DOBEREINER, J. Nodulação e fixação de nitrogênio em leguminosas florestais. Pesquisa Agropecuária Brasileira, Brasília, v. 19, p. 83-90, 1984.

DOWLING, D. N.; BROUGHTON, W. J. Competition for Nodulation of Legumes. Annual Review Microbiology, [S.1.], v. 40, p. 131-57, 1986.

FELFILI, J. M. et al. Composição florística e fitossociologia do cerrado sentido restrito no município de Água Boa - MT. Acta Botanica Brasilica, Belo Horizonte, v. 16, n. 1, p. 103-112, 2002.

GIÁCOMO, R. G. et al. Florística e fitossociologia em áreas de campo sujo e cerrado sensu stricto na Estacão Ecológica de Pirapitinga-MG. Ciência Florestal, Santa Maria, v. 23, n. 1, p. 29-43, 2013. 
GOMES, L. et al. Comparações florísticas e estruturais entre duas comunidades lenhosas de cerrado típico e cerrado rupestre, Mato Grosso, Brasil. Acta Botanica Brasilica, Belo Horizonte, v. 25 , n. 4 , p. $865-875,2011$.

GUILHERME, F. A. G.; OLIVEIRA, A. S. Estrutura populacional de Butia purpuracens Glassman (Arecaceae) em duas ares de cerrado sensu stricto no estado de Goias. Revista de Biologia Neotropical, Goiânia, v. 7, n. 1, p. 37-45, 2011.

GUILHERME, F. A. G. et al. Vegetative and reproductive phenology of Butia purpurascens Glassman (Arecaceae) under the effects of leaf harvesting. Brazilian Journal of Biology, Curitiba, v. 75, n. 1, p. 77-85, 2015.

HARIDASAN, M. Nutrição mineral de plantas nativas do cerrado. Revista Brasileira de Fisiologia Vegetal, Campinas, v. 12, n. 1, p. 54-64, 2000.

HOFFMANN, W. A.; MOREIRA, A. G. The role of fire in population dynamics of woody plants. In: OLIVEIRA, P. S.; MARQUIS, R. J. (Ed.). Cerrados of Brazil. New York: Columbia University Press, 2002. p. 159-177.

KLINK, C. A.; MACHADO, R. B. A conservação do Cerrado brasileiro. Megadiversidade, Belo Horizonte, v. 1, n. 1, 2005.

KOTTEK, M. et al. World Map of the Köppen-Geiger climate classification updated. Meteorologische Zeitschrift, Stuttgart, v. 15, n. 3, p. 259-263, jun. 2006.

LENZA, E. et al. Comparação da vegetação arbustivo-arbórea de uma área de cerrado rupestre na Chapada dos Veadeiros, Goiás, e áreas de cerrado sentido restrito do Bioma Cerrado. Revista Brasileira de Botânica, São Paulo, v. 34, n. 3, p. 247-259, 2011.

LENZA, E. et al. Species composition, diversity, and vegetation structure in a gallery forestcerrado sensu stricto transition zone in eastern Mato Grosso, Brazil. Acta Botanica Brasilica, Belo Horizonte, v. 29, n. 3, p. 327-338, 2015.

LIMA, T. A. et al. Florística e estrutura da vegetação arbustivo-arbórea em uma área de cerrado rupestre no Parque Estadual da Serra de Caldas Novas, Goiás. Biota Neotropica, São Paulo, v. 10, n. 2, p. 159-166, 2010.

MAGURRAN, A. E. Medindo a diversidade biológica. Curitiba: Universidade Federal do Paraná, 2011.

MARACAHIPES, L. et al. Estrutura e composição florística da vegetação lenhosa em cerrado rupestre na transição Cerrado-Floresta Amazônica, Mato Grosso, Brasil. Biota Neotropica, São Paulo, v. 11, n. 1, p. 133-141, 2011.

MARIMON-JÚNIOR, B. H.; HARIDASAN, M. Comparação da vegetação arbórea e características edáficas de um cerradão e um cerrado sensu stricto em áreas adjacentes sobre solo distrófico no leste de Mato Grosso, Brasil. Acta Botanica Brasilica, Belo Horizonte, v. 19, n. 4, p. 913-926, 2005.

MEDEIROS, M. B. DE; WALTER, B. M. T. Composição e estrutura de comunidades arbóreas de cerrado stricto sensu no norte do Tocantins e sul do Maranhão. Revista Árvore, Viçosa, MG, v. 36, n. 4, p. 673-683, 2012.

MEIRA-NETO, J. A. A.; SAPORETTI-JÚNIOR, A. W. Parâmetros fitossociológicos de um cerrado no Parque Nacional da Serra do Cipó, MG. Revista Árvore, Viçosa, MG, v. 26, n. 5, p. 645-648, 2002. 
MENDONÇA, R. C. et al. Flora vascular do bioma Cerrado: checklist com 12.356 espécies. In: SANO, S. M.; ALMEIDA, S. P. DE; RIBEIRO, J. F. (Ed.). Cerrado: ecologia e flora. Brasília: Embrapa; CPAC, 2008.

MIRANDA, H. S. et al. Queimadas de Cerrado: caracterização e impactos. In: AGUIAR, L. M. D. S.; CAMARGO, A. J. A. (Ed.). Cerrado: ecologia e caracterização. Planaltina: EMBRAPA Cerrados, 2004. p. 249.

MIRANDA, H. S. et al. The fire factor. In: OLIVEIRA, P. S.; MARQUIS, R. J. (Ed.). Cerrados of Brazil. New York: Columbia University Press, 2002. p. 51-68.

MIRANDA, H. S. et al. Mortalidade de plantas lenhosas do cerrado sensu stricto submetidas a diferentes regimes de queima. In: IMPACTOS de Queimadas em Áreas de Cerrado e Restinga. Brasília: ECL; Universidade de Brasília., 1996. p. 102-111.

MOREIRA, A. G. Effects of fire protection on savanna structure in Central Brazil. Journal of Biogeography, Oxford, v. 27, p. 1021-1029, 2000.

MUELLER-DOMBOIS, D.; ELLENBERG, H. Aims and methods of vegetation ecology. New York: John Wiley \& Sons, 1974.

MUELLER, C. C.; MARTINE, G. Modernização da agropecuária, emprego agrícola e êxodo rural no Brasil - A década de 1980. Revista de Economia Política, São Paulo, v. 17, n. 3, p. 85-104, 1997.

NERI, A. V. et al. Análise da estrutura de uma comunidade lenhosa em área de cerrado sensu stricto no município de Senador Modestino Gonçalves, norte de Minas Gerais, Brasil. Revista Árvore, Viçosa, MG, v. 31, n. 1, p. 123-134, 2007.

OLIVEIRA-FILHO, A. T.; RATTER, J. A. Vegetation physiognomies and woody flora of the cerrado biome. In: OLIVEIRA, P. S.; MARQUIS, R. J. (Ed.). The Cerrados of Brazil. New York: Columbia University Press, 2002. p. 91-120.

PINTO, J. R. R. et al. Composição florística e estrutura da vegetação arbustivo-arbórea em um cerrado rupestre, Cocalzinho de Goiás, Goiás. Revista Brasileira de Botânica, São Paulo, v. 32, n. 1, p. 1-10, 2009.

RATTER, J. A. et al. Analysis of the floristic composition of the brazilian Cerrado vegetation III: comparison of the woody vegetation of 376 areas. Edinburgh Journal of Botany, Cambridge, v. 60, n. 1, p. 57-109, 2003.

REATTO, A. et al. Solos do Bioma Cerrado: aspectos pedológicos. In: SANO, S. M.; ALMEIDA, S. P.; RIBEIRO, J. F. (Ed.). Cerrado: ecologia e flora. Planaltina: Embrapa; CPAC, 2008.

RIBEIRO, J. F.; WALTER, B. M. T. As principais Fitofisionomias do Bioma Cerrado. In: SANO, S. M.; ALMEIDA, S. P.; RIBEIRO, J. F. (Ed.). Cerrado: ecologia e flora. Planaltina: Embrapa; CPAC, 2008. p. 151-199.

RIOS, M. N. S. et al. Mudanças pós-fogo na florística e estrutura da vegetação arbóreo-arbustiva de um cerrado sentido restrito em Planaltina, DF. Ciência Florestal, Santa Maria, v. 28, n. 2, p. 469-482, 2018.

SANO, E. E. et al. Land cover maping of the tropical savanna region in Brazil. Environmental Monitoring and Assessment, Dordrecht, v. 166, p. 113-124, 2010.

SIEGEL, S. Estatística não paramétrica para as ciências do comportamento. São Paulo: McGraw-Hill do Brasil, 1975. 
SOLÓRZANO, A. et al. Perfil florístico e estrutural do componente lenhoso em seis áreas de cerradão ao longo do bioma Cerrado. Acta Botanica Brasilica, Belo Horizonte, v. 26, n. 2, p. 328-341, 2012.

SPERA, S. T. et al. Atributos físicos de solos e distribuição das fitofisionomias de Cerrado na Bacia Hidrográfica do Rio Jardim, DF. Boletim de Pesquisa e Desenvolvimento - EMBRAPA Cerrados, Brasília, v. 146, 2005.

ZAR, J. H. Biostatistical analysis. New Jersey: Prentice-Hall, 2009. 